\title{
A MISSÃO SOCIAL DA UTFPR DESDE SUA FUNDAÇÃO E OS SILÊNCIOS QUANTO ÀS DESIGUALDADES RACIAIS
}

\author{
Ana Crhistina Vanali ${ }^{1}$ \\ Andrea Maila Voss Kominek²
}

\begin{abstract}
RESUMO: A presente pesquisa visa conhecer as bases de fundação da atual Universidade Tecnológica Federal do Paraná (UTFPR) para, a partir do resgate de sua história e origens, compreender a "missão social" que se propôs e refletir sobre a implementação desta missão ao longo de sua história e suas transformações ao longo do tempo. Num primeiro momento, realiza-se a análise das legislações que permitiram a criação da Escola de Aprendizes e Artífices; suas transformações em CEFET-PR; e posteriormente, em UTFPR. Tendo em vista a missão social assumida pela instituição desde sua fundação, a pergunta que norteia da análise das informações coletadas, visa investigar se este espaço de ensino profissional, técnico e tecnológico constituíram um espaço de desconstrução de desigualdades sociais quanto a uma temática específica: as desigualdades raciais. Num segundo momento, investiga-se, através da análise dos dados institucionais disponíveis, a possibilidade de compreender este espaço de ensino como espaço de inclusão de uma comunidade tradicionalmente excluída e desatendida socialmente: as comunidades negras. Num terceiro momento, discute-se a atualidade da "missão social" de fundação e faz-se uma breve reflexão sobre a implementação do sistema de cotas raciais na UTFPR. Finaliza-se o artigo com indicações de aspirações possíveis a serem conquistadas na desconstrução das desigualdades raciais na instituição.
\end{abstract}

Palavras-Chave: UTFPR. Missão social. Desigualdade racial. Cotas.

\section{UTFPR'S SOCIAL MISSION SINCE ITS FOUNDATION AND THE SILENCE OF}

\section{RACIAL INEQUALITIES}

\begin{abstract}
The present research aims at knowing the foundations of the current Federal Technological University of Paraná (UTFPR), from the rescue of its history and origins, to understand the "social mission" that was proposed and to reflect on the implementation of this mission to the Throughout its history and its transformations over time. At first, the analysis of the legislation that allowed the creation of the School of Apprentices and Craftsmen is carried out; Their transformations in CEFET-PR; And later, in UTFPR. Considering the social mission assumed by the institution since its foundation, the question that guides the analysis of the collected information, aims to investigate if this space of professional, technical and technological education constituted a space of deconstruction of social inequalities on a specific theme: Racial inequalities. Secondly, through the analysis of available institutional data, we investigate the possibility of understanding this teaching space as a space for inclusion of a community traditionally excluded and neglected socially: black communities. In a third moment, the current "social mission" of foundation is discussed and a brief reflection is made on the implementation of the system of racial quotas in UTFPR. The article ends with indications of possible aspirations to be achieved in the deconstruction of racial inequalities in the institution.
\end{abstract}

Keywords: UTFPR. Social mission. Racial inequality. Quotas

- Enviado em 13/05/2017

- Aprovado em 28/06/2017

\footnotetext{
${ }^{1}$ Professora de Sociologia da UTFPR. E-mail: anacvanali@yahoo.com.br

${ }^{2}$ Professora de Filosofia da UTFPR. E-mail: amvkominek@gmail.com
} 


\section{DE ESCOLA DE APRENDIZES À UNIVERSIDADE TECNOLÓGICA}

A história da Universidade Tecnológica Federal do Paraná - UTFPR teve início em 1909 com a criação das Escolas de Aprendizes Artífices em várias capitais do país pelo então presidente, Nilo Peçanha, em 23 de setembro de 1909. No Paraná, a escola foi inaugurada no dia 16 de janeiro de 1910, em um prédio da Praça Carlos Gomes. O objetivo desta escola era ensinar ofícios profissionais a crianças e jovens pobres, órfãos e até abandonados que viviam pelas ruas em situação que hoje chamaríamos de risco. Os ofícios ensinados eram tipicamente urbanos, adequados às necessidades de mercado daquele tempo, voltados ao setor de prestação de serviços e também da incipiente indústria paranaense, ligada a erva-mate, madeira e suas atividades acessórias. Ministravam-se cursos de alfaiataria, serralheria, marcenaria, selaria, pintura ornamental e sapataria, ofícios ensinados por mestres que eram práticos em suas atividades (QUELUZ, 2010).

Esse ensino destinado aos garotos de camadas menos favorecidas da sociedade, chamados de "desprovidos da sorte", era em tempo integral. Pela manhã, recebiam conhecimentos elementares (ensino primário como ler, escrever, calcular) e, à tarde, aprendiam as disciplinas técnicas de cada ofício. Inicialmente, havia apenas 45 alunos matriculados na escola. Aos poucos, a escola cresceu, passou a ofertar oficinas de pintura decorativa e escultura ornamental. Com o aumento do número estudantes, fez-se necessária a procura por uma sede maior. Então, em 1936, ocorreu a transferência para a Avenida Sete de Setembro com a Rua Desembargador Westphalen, onde permanece até hoje. O ensino tornou-se cada vez mais profissional até que, no ano de 1937, a escola começou a ministrar o ensino de 1으 grau, passando a ser denominada Liceu Industrial do Paraná.

Em 1942, a organização do ensino industrial foi realizada em todo o país. A partir disso, o ensino passou a ser ministrado em dois ciclos. No primeiro, havia o ensino industrial básico, o de mestria e o artesanal. No segundo, o técnico e o pedagógico. Com a reforma, foi instituída a rede federal de instituições de ensino industrial e o Liceu passou a chamar-se Escola Técnica de Curitiba. No ano seguinte, tiveram início os primeiros cursos técnicos: Construção de Máquinas e Motores, Edificações, Desenho Técnico e Decoração de Interiores. Antes dividido em ramos diferentes, em 1959, o ensino técnico no Brasil foi unificado pela legislação. A escola ganhou, assim, maior autonomia e passou a chamar-se Escola Técnica Federal 
do Paraná. Em 1974, foram implantados os primeiros cursos de curta duração de Engenharia de Operação (Construção Civil e Elétrica) (GURSKI JUNIOR, 2010).

No ano de 1978, a Escola Técnica foi transformada em Centro Federal de Educação Tecnológica do Paraná (CEFET-PR), passando a ministrar também cursos de graduação. Com a implantação dos cursos superiores, ocorre a criação dos programas de pós-graduação nas décadas de 1980 e 1990. Em 1990, o Programa de Expansão e Melhoria do Ensino Técnico fez com que o CEFET-PR expandisse para o interior do Paraná, realizando a implantação de outras unidades (AMORIM, 2010).

Com a Lei de Diretrizes e Bases da Educação (LDBE), de 1996, não é mais permitida a oferta dos cursos técnicos integrados, então ocorre a implantação do Ensino Médio e dos cursos de Tecnologia. Em 1998, em virtude das legislações complementares à LDBE, a diretoria do então CEFET-PR criou um projeto de transformação da Instituição em Universidade Tecnológica. 0 projeto tornou-se lei no dia 7 de outubro de 2005 e o CEFET-PR passou a ser a UNIVERSIDADE TECNOLÓGICA FEDERAL DO PARANÁ (UTFPR), a primeira especializada do Brasil. Atualmente, a UTFPR conta com 13 campi, distribuídos nas cidades de Apucarana, Campo Mourão, Cornélio Procópio, Curitiba, Dois Vizinhos, Francisco Beltrão, Guarapuava, Londrina, Medianeira, Pato Branco, Ponta Grossa, Santa Helena e Toledo (TEIXEIRA, 2010).

Recapitulando as diferentes denominações da trajetória da UTFPR: - 1909 - Escola de Aprendizes Artífices do Paraná

- 1937 - Liceu Industrial do Paraná

- 1942 - Escola Técnica de Curitiba

- 1959 - Escola Técnica Federal do Paraná

- 1978 - Centro Federal de Educação Tecnológica do Paraná - Cefet-PR

- 2005 - Universidade Tecnológica Federal do Paraná - UTFPR

A hoje centenária UTFPR, surgida no início do século XX com a missão de atender os "desvalidos da sorte e excluídos sociais" para formá-los e, desta forma, promover sua inclusão no mercado de trabalho, gradativamente passou a assumir novos ares, objetivos e dimensões (físicas, políticas e sociais). Ao transformar-se em universidade sofreu transformações em seu público de 
discentes, que passa a ser, então, majoritariamente de classe média, quase que exclusivamente de alunos do gênero masculino e brancos. Poucas são as exceções do gênero feminino e ainda em menor número as de negros e negras. O novo desafio colocado atualmente à instituição, com a implantação do sistema de cotas raciais $^{3}$, trazendo um público que até então se encontrava dela excluído, são as novas demandas e as necessárias adaptações e adequações de um sistema que possui dificuldades em superar os entraves históricos do racismo estrutural da sociedade brasileira.

\section{ESPAÇO DE ENSINO - ESPAÇO DE INCLUSÃO}

Atualmente, a UTFPR conta com unidades educacionais em 13 municípios do Paraná, oferecendo cursos em diversos níveis e áreas: Técnicos, Tecnologias, Bacharelados, Licenciaturas, Especializações, Mestrados, Doutorados, Formação de Professores (COFOP) e Extensão, além de oferecer cursos de especialização na modalidade Ensino a Distância, por meio do Sistema Universidade Aberta do Brasil (UAB) - programa criado pelo Ministério da Educação em 2005.

A partir de 2010, a seleção de estudantes para os cursos de graduação passou a ser realizada pelo Sistema de Seleção Unificada (SiSU), do Ministério da Educação, que classifica os estudantes de acordo com a nota obtida no Exame Nacional do Ensino Médio (Enem). Tal modificação contribuiu significativamente para a ampliação do horizonte geográfico de discentes atendidos pela instituição, uma vez que tornou-se mais viável e provável a vinda de alunos e alunas de diferentes regiões do país. Uma situação que por si só, representa um aumento considerável na diversidade cultural e étnico-racial em seu corpo discente. Se, por um lado tal diversidade constitui significativa riqueza cultural, por outro, pode representar um desafio adicional para a harmonia e bom funcionamento das atividades docentes, caso não sejam bem aproveitadas.

${ }^{3}$ Lei de Cotas. no 12.711/2012: garante a reserva de 50\% das matrículas por curso e turno nas 59 universidades federais e 38 institutos federais de educação, ciência e tecnologia a alunos oriundos integralmente do ensino médio público, em cursos regulares ou da educação de jovens e adultos. Os demais $50 \%$ das vagas permanecem para ampla concorrência. Disponível em http://www.planalto.gov.br/ccivil 03/ ato2011-2014/2012/Lei/L12711.htm. Acesso em 2.dez.2016. 
Assim, mais do nunca em sua história, hoje a UTFPR necessita conhecer e compreender quem é seu público e assumir verdadeiramente sua missão social, pois muito mais do que formadora de "técnicos e engenheiros", formadora de "mão de obra especializada", precisa ser formadora de "bons cidadãos", conscientes e responsáveis de suas escolhas e decisões. Para que isto aconteça, no entanto, é preciso que ocorra a valorização do aluno como um todo, como um ser humano a ser contemplado de forma plena e não apenas como um técnico a ser treinado para o mercado de trabalho. Assim, cidadania está intrinsecamente ligada à autonomia, reflexão crítica e participação ativa na sociedade.

A este respeito Milton Santos (1998) faz interessantes observações. Segundo ele, sob o pretexto de formar estudantes competitivos para o mercado de trabalho globalizado, o saber filosófico é preterido como desnecessário em função de saberes práticos reduzidos a processos de treinamento. ${ }^{4} \mathrm{~A}$ escola, ao fazer esta opção, deixa de ser o lugar de formação de verdadeiros cidadãos para tornar-se um celeiro de "deficientes cívicos", desprovidos das noções clássicas como democracia, república, cidadania e individualidade.

Neste sentido, torna-se fundamental, como sugere Bastos (1998, p. 60), que a educação seja compreendida como "a reconstrução permanente da experiência humana, pois busca imprimir sentido ao curso da vida, afinal sua capacidade de dirigir e intervir nas caminhadas da história dos homens é grande". A educação tecnológica, especificamente, assume, assim, a tarefa de:

Registrar, sistematizar, compreender e utilizar o conceito de tecnologia, histórica e socialmente construído, para dele fazer elemento de ensino, pesquisa e extensão, numa dimensão que ultrapasse os limites das simples aplicações técnicas, como instrumento de inovação e transformação das atividades econômicas em benefício do homem, enquanto trabalhador, e do país. (BASTOS, 1998, p.32)

A importância de que esta formação cidadã e humana, através de uma formação geral, seja ofertada pela escola, para além da formação técnica, é fundamental. Nas empresas pode existir, eventualmente, preocupação em fornecer formação profissional ou treinamento técnico aos seus

\footnotetext{
${ }^{4}$ Artigo publicado pelo jornal Folha de São Paulo em 1998 e incrivelmente atual no contexto nacional devido à proposta de medida provisória de reforma no ensino médio - PL 6840/2013 - onde as disciplinas de Filosofia e Sociologia passaram a ser opcionais no currículo escolar. Disponível em http://www.camara.gov.br/proposicoesWeb/fichadetramitacao?idProposicao=602570..$\quad$ Acesso em 13.novembro.2016.
} 
empregados, porém, dificilmente existe a preocupação com sua formação geral enquanto indivíduo. Encarada sob esta perspectiva, portanto, a educação tecnológica permite uma democratização do conhecimento tradicionalmente negado aos trabalhadores pelo sistema produtivo, permitindo a este trabalhador acesso a discussões que, de outra forma, delas estaria excluído. A escola atende, assim, às duas grandes aspirações do cidadão: formação profissional e participação política plena na cidadania e na democratização do saber. Segundo Kuenzer (1992, p. 88) "a necessidade de formação básica sólida nas áreas das ciências humanas, sociais e exatas; por trás desta evidência está o reconhecimento de que a formação do cidadão exige a compreensão da organização social, além do domínio da ciência e da tecnologia".

No caso da educação tecnológica ofertada pela UTFPR, uma instituição centenária, de excelência reconhecida nacionalmente e com uma importante missão social, é preciso que ambos os interesses sejam atendidos: formação técnica, instrumental e formação cidadã plena. Para que isto ocorra, no entanto, é necessário que se compreenda tecnologia de modo amplo, pois, como aponta Carvalho (1997, p.71), "na mesma medida em que não se pode falar em tecnologia sem considerar as transformações sociais que estão ao mesmo tempo provocando e favorecendo seu desenvolvimento, também não se pode analisar a sociedade sem que se leve em consideração as transformações tecnológicas que estão ocorrendo dentro dela".

Se por um lado, o avanço tecnológico afeta a vida de todos os seres humanos do planeta, pagando todos igualmente a conta através da poluição, concentração populacional em áreas urbanas e destruição da natureza, por outro, nem todos têm acesso aos seus benefícios. É preciso lembrar que a lógica do capitalismo, do lucro como objetivo central, é consequência da inicial busca do ser humano por controlar e dominar a natureza, além da histórica consolidação do modo de produção industrial, inaugurado pela revolução industrial e reforçado pelas inovações tecnológicas. Tal lógica acabou por absorver a tecnologia em proveito próprio, ou seja, utilizandoa para o fortalecimento e expansão do próprio capitalismo, desconsiderando o aspecto humano e as relações sociais.

O desenvolvimento tecnológico é visto pelos que dele participam como um fenômeno que por si só é positivo, pois significa o progresso e este é sempre intrinsecamente bom. $\mathrm{Na}$ sociedade ocidental moderna, progresso quer dizer a utilização de tecnologias cada vez mais avançadas que supostamente melhorariam a qualidade de vida de todos. (CARVALHO, 1997, p. 71). 
Tal absorção conduziu, gradualmente, á atual situação na qual as vantagens resultantes da tecnologia encontram-se restritas a um pequeno e privilegiado grupo, em detrimento da sociedade como um todo, pois, como aponta Figueiredo (1989, p.13):

O avanço tecnológico, nas sociedades industriais contemporâneas, visa, teoricamente, à produção de mercadorias que, em termos imediatos, garantem o lucro e, a médio e longo prazos, asseguram a própria reprodução do sistema social. Tal fato não implica, porém, homogeneidade de criação de tecnologias e nem, tampouco, que as tecnologias deixem de provocar efeitos contraditórios nos contextos onde são produzidas e absorvidas.

Ora, uma instituição educacional como a UTFPR, que nasceu imbuída da missão social de assistir os "desvalidos da sorte e excluídos sociais", precisa levar estas questões em consideração e, mais ainda, toma-las como central em suas ações e prioridades. Apesar de propor a missão social desde suas origens, no entanto, a instituição sempre priorizou o técnico e tecnológico, relegando às "humanidades" um papel complementar, ou na linguagem dos próprios discentes, de "perfumaria". Apesar das boas intenções e da oferta de diversas atividades extracurriculares com grande qualidade, em nível de excelência e de reconhecimento nacional, como o Coral, as Bandas Marcial e Musical, o Grupo de Teatro e diversas modalidades esportivas, a instituição nunca se debruçou profundamente sobre os aspectos de formação humana plena, de forma central.

Até mesmo a tentativa de valorizar o aspecto humano, ao escolher o título para si mesma como "Tecnologia e Humanismo", pouco avançou para além do estético formal e de marketing, pois no próprio título, a tecnologia encontra-se separada do humano pelo conectivo "e", como se a própria tecnologia já não fosse, em si, profundamente humana. Se existe, na instituição, um "Departamento de Humanas", o que seriam os demais departamentos? Desumanos? A matemática ou a física, não seriam humanas? A tecnologia, não é humana?

Ora, tecnologia é um fenômeno social, cultural, histórico. É resultado das necessidades, sonhos e trabalho dos seres humanos. É, portanto, essencialmente humana, ainda que alguns teimem em tentar fazê-la parecer neutra e fria. Cabe aos seres "humanos", escolher, construir e implementar a tecnologia que nos fortaleça, nos honre e promova. A fé em uma pseudoneutralidade da tecnologia e, principalmente, em seu valor exclusivamente positivo, tem conduzido a humanidade a uma perigosa e ingênua postura perante seus efeitos. 
Se a tecnologia não pode ser entendida de forma neutra e isolada, igualmente os seres humanos, discentes e docentes, não podem ser entendidos de forma genérica, neutra. Cada ser humano possui suas especificidades, formação, cultura e identidade. Ao tratar os sujeitos de forma universal, desconsiderando suas especificidades, em nome de uma pretensa "inclusão de todos", afinal "somos todos humanos", o que se propicia é a perpetuação das desigualdades e da injustiça, uma vez que todos são iguais perante a constituição, mas tratados de forma diferente, como comprovam, por exemplo, os assustadores índices oficiais referentes aos assassinatos do povo negro e as diferenças salariais entre homens e mulheres, entre brancos e negros. ${ }^{5}$

Apesar de propor-se "inclusiva", a forma universal de tratar os indivíduos, a suposta "democracia racial" ou "amabilidade típica do brasileiro" gera conflitos estruturantes da sociedade, uma vez que o suposto sujeito "neutro cartesiano", é essencialmente um sujeito eurocêntrico, branco e masculino. Assim, a tradição cultural eurocêntrica e androcêntrica encontra-se estruturalmente presente no meio universitário e científico e permeia de forma subliminar o pensamento, os conceitos, as prioridades e as escolhas dos teóricos da ciência e da tecnologia. Para que isto seja superado, é preciso assumir o sujeito para além do teórico-universal, um sujeito corporificado, com especificidades e desafios particulares. Um sujeito com corpo, com demandas, e crenças de seu próprio povo, sua cultura e origens.

\footnotetext{
${ }^{5}$ Ver os números do Mapa da Violência, que revelou que, entre 2002 e 2012, a taxa de homicídios da população branca caiu $24,8 \%$, enquanto a da população negra ascendeu $38,7 \%$, significando que os negros morreram $72 \%$ mais que os brancos. Disponível em http://www.mapadaviolencia.org.br/. Acesso 13.dezembro.2016. Ver também pesquisa mensal de emprego (PME) do Instituto Brasileiro de Geografia e Estatística (IBGE) que revela que trabalhadores de cor preta ou parda ganham, em média, muito menos do que os indivíduos de cor branca no Brasil. Um trabalhador negro no Brasil ganha, em média, pouco mais da metade $(57,4 \%)$ do rendimento recebido pelos trabalhadores de cor branca. Em termos numéricos, estamos falando de uma média salarial de $\mathrm{R} \$ 1.374,79$ para os trabalhadores negros, enquanto a média dos trabalhadores brancos ganham R\$ 2.396,74. Disponível em http://www.ibge.gov.br/home/estatistica/indicadores/trabalhoerendimento/pme nova/. Acesso 13.dezembro.2016. O Brasil apresenta um dos maiores níveis de disparidade salarial. No país, os homens ganham aproximadamente $30 \%$ a mais que as mulheres de mesma idade e nível de instrução, quase o dobro da média da região (17,2\%), enquanto na Bolívia a diferença é muito pequena. O resultado é o mesmo no que diz respeito à disparidade por raça e etnia, que chega também a 30\%. Disponível em http://www.observatoriodegenero.gov.br/menu/noticias/homens-recebemsalarios-30-maiores-que-as-mulheres-no-brasil/. Acesso em 13.dezembro.2017.
} 


\section{COTAS NA UTFPR E A QUESTÃO DA INCLUSÃO}

A lei $12.711 / 2012$ estabeleceu a reserva de $50 \%$ do total de vagas das universidades e institutos federais para discentes que cursaram o ensino médio na rede pública, sendo que $25 \%$ desse percentual deve seguir critérios raciais, correspondente ao da soma de pretos, pardos e indígenas no Estado, de acordo com o último censo do IBGE (Instituto Brasileiro de Geografia e Estatística) (BRASIL, 2012). Assim, as vagas reservadas às cotas são subdivididas, sendo metade para estudantes de escolas públicas com renda familiar bruta igual ou inferior a um salário mínimo e meio per capita e metade para estudantes de escolas públicas com renda familiar superior a um salário mínimo e meio. Sendo por fim, também para cada subgrupo, levado em conta o percentual mínimo correspondente ao da soma de pretos, pardos e indígenas no estado, de acordo com o referido censo.

As medidas propostas por leis como a 12.711/2012 (Lei de cotas), e a lei 10639/2002 (Lei de obrigatoriedade do ensino da História e Cultura Africana), visam diminuir a gritante desigualdade existente na sociedade brasileira e amparar os grupos sociais que se encontram em situação de vulnerabilidade, como pode-se observar através dos dados estatísticos oficiais de vulnerabilidade e exclusão social dos negros no Brasil: em 2014, pardos e negros representam $53,6 \%$ da população brasileira, sendo $76 \%$ dos mais pobres do país; dados do Censo 2010 indicaram que dentre os jovens de 15 a 24 anos que cursam o ensino superior, 31,1\% são brancos, $13,4 \%$ pardos e $12,8 \%$ pretos. Outro dado indica que em 2015 , os negros receberam cerca de $59,2 \%$ do salário de um branco (IBGE, 2012) ${ }^{6}$

No caso específico da UTFPR, a lei de cotas foi aplicada de forma gradual em seus sistemas de seleção para o ensino técnico integrado e superior, iniciando com um percentual de 12,5\% em 2013, atingindo atualmente o percentual de $25 \%$ de cotas raciais. No entanto, embora a lei englobe negros e indígenas, percebe-se uma maior visibilidade e debate em relação à população negra, uma vez que sua presença é mais forte do que a da população indígena. Dados do último

6 IBGE (2012). Censo 2010 mostra as características da população brasileira. Disponível em:< http://www.brasil.gov.br/educacao/2012/07/censo-2010-mostra-as-diferencas-entre-caracteristicas-gerais-dapopulacao-brasileira>. Acesso em: 10 maio 2016. 
censo de 2010, do IBGE indicaram que no Paraná $27,4 \%$ da população se autodeclarou negro ou pardo e apenas 1,3\% amarela ou indígena (IBGE, 2016) ${ }^{7}$.

Assim, a partir da implantação da política de cotas raciais na seleção de seus alunos nos vestibulares de 2013, a partir de 2014, a UTFPR passa a receber em seu quadro discente, alunos negros. Negros e negras passam a circular como alunos e alunas pelos corredores da instituição , ainda que em número reduzido e desproporcional com a diversidade estatística encontrada na população brasileira fora das universidades ${ }^{9}$. Esta nova realidade, que constitui apenas uma pequena amostra do que ocorre nas universidades em todo o país, traz novas demandas e exige, por parte de gestores, docentes e técnicos, ações, conhecimentos e posturas para as quais não foram formados ou preparados. Apesar das boas intenções existirem, muitas vezes falta conhecimento e informação de fácil acesso para a formação plena dos quadros de pessoal das universidades, diante destas novas demandas.

Trata-se de uma conjuntura política, cultural e social que exige um olhar atento à diversidade que passa a abrigar em seus ambientes acadêmicos. É preciso preparar-se e transformar-se para esta nova realidade e para que este ambiente se torne, de fato, como propunha a missão assumida desde a fundação desta instituição, um espaço de inclusão e correção das injustiças e desigualdades sociais.

Assim, a importância de superar a injustiça histórica causada por anos de escravidão e todas as consequências dela decorrentes, como o racismo ${ }^{10}$, em todas as suas formas, torna-se

7 IBGE (2016). Síntese de indicadores sociais 2010. Disponível em: <http://biblioteca.ibge.gov.br/visualizacao/livros/liv66777.pdf. >. Acesso em: 20 maio 2016.

${ }^{8}$ Em novembro de 2015 foi criado o Coletivo Negro Enedina N da UTFPR, a partir da necessidade de estudantes negros e negras se organizarem para se fortalecerem enquanto pessoas negras, sendo assim uma forma de combate ao racismo e de permanência (resistência) dentro da universidade, um local que historicamente se configura como de exclusão da população negra.

9 Disponível em http://www.ibge.gov.br/home/estatistica/populacao/censohistorico/1550 1870.shtm. Acesso em 3.dezembro.2016. Ver também http://economia.uol.com.br/noticias/redacao/2015/12/04/negros-representam-54da-populacao-do-pais-mas-sao-so-17-dos-mais-ricos.htm e http://www.sae.gov.br/imprensa/noticia/materias/bancode-dados-mostra-situacao-da-populacao-negra-do-brasil/. Acesso em 3.dezmbro.2016.

${ }^{10}$ A respeito da cultura racista, BENTO (2003, p.25-26), explicita que, "constata-se que foi um processo inventado e mantido pela elite branca brasileira, embora apontado por essa mesma elite como um problema do negro brasileiro. Considerando (ou quiçá inventando) seu grupo como padrão de referência de toda uma espécie, a elite fez uma apropriação simbólica crucial que vem fortalecendo a autoestima e o autoconceito do grupo branco em detrimento dos demais, e essa apropriação acaba legitimando sua supremacia econômica, política e social.” (...) Assim, o que 
uma necessidade premente conhecer as raízes que formaram nossa sociedade, através da reflexão sobre os conceitos de Africanidade e Ancestralidade Africana. ${ }^{11} 12$

Criar oportunidades de tematização, explicitação e correção destes problemas estruturais, torna-se fundamental para a criação de um ambiente universitário justo, igualitário e democrático, situação que contribuirá grandemente para que os alunos e alunas por ela formados tornem-se não apenas bons profissionais, mas principalmente profissionais zelosos de si, e da sociedade a qual vivem, constroem e participam. Profissionais que assumem suas responsabilidades, antes de mais nada, como cidadãos e seres humanos plenos.

\section{CONSIDERAÇÕES FINAIS}

Medeiros (2015) reconhecendo a exclusão dos negros nas universidades, discutiu o impacto da política de cotas, analisando o ingresso e permanência de alunas e alunos negros na UTFPR, a partir da lei $n^{\circ} 12.711 / 2012$ que inicia em 2013 na UTFPR. Nesses dois primeiros anos teve um processo de inclusão de alunas e alunos negras (os) nos cursos de engenharias, mas este número que corresponde a um universo de 30\% em relação ao percentual de cotistas ainda é baixo e apresenta poucas mulheres negras nas engenharias assim como nas licenciaturas. Os homens negros têm aumentado gradativamente nas engenharias, melhorando seus índices de forma geral, mas as mulheres negras têm diminuído, além de apresentar os coeficientes de rendimento mais baixos. As mulheres não-cotistas de forma geral apresentam os melhores

parece interferir neste processo é uma espécie de pacto, um acordo tácito entre os brancos de não se reconhecerem como parte absolutamente essencial na permanência das desigualdades raciais no Brasil."

${ }^{11}$ As categorias Africanidades e/ou Ancestralidade Africana significam sinteticamente tais universos culturais, por meio dos quais os indivíduos e grupos originários constituíam-se a si mesmos como sujeitos históricos. Embora houvesse o princípio de reunir gente negra de regiões, idiomas e parâmetros culturais diferentes, no intuito de facilitar o controle sobre os corpos, determinados elementos das diferentes culturas seguiam padrões que aproximavam as pessoas, contribuindo para a manutenção da vigília e disposição de reaver a liberdade.

${ }^{12}$ A criação e implementação, nos últimos anos, de leis federais que amparam e legislam a questão racial e, mais especificamente a obrigatoriedade do ensino da cultura e história africanas por instituições públicas de ensino, especialmente a nível federal, trouxeram uma nova realidade e novos desafios para o interior das escolas. Consultar Lei 10.639/2003 que versa sobre obrigatoriedade do ensino da história e cultura afro-brasileira (disponível em https://www.planalto.gov.br/ccivil 03/leis/2003/L10.639.htm. Acesso 2.dez.2016) e Lei 0307/2015 que versa sobre o respeito e a valorização da diversidade étnico-racial, que, entre outros, constituem princípios vitais para a melhoria e democratização da gestão e do ensino, nos níveis, básicos, fundamentais, de graduação e pós-graduação. 
desempenhos constatando-se um resultado das lutas feministas para a inclusão das mulheres nas ciências.

O desafio é grande. Apesar dos números ainda serem pequenos, houve uma porcentagem de negros que puderam ter acesso à universidade e tem superado inúmeras dificuldades para a sua permanência, porém ainda há uma grande evasão devido a reprovações no $1^{\circ}$ período. Apesar de haver novas demandas para o novo contexto político, social e cultural, não parece haver, no entanto, ações que encaminhem a necessária adaptação.

É preciso construir informação e conhecimento que possam subsidiar o trabalho de docentes e gestores na implantação de políticas de promoção à igualdade racial e combate ao racismo, cumprindo, desta forma, com a missão originária da instituição UTFPR: atender os excluídos sociais. Como a instituição, atualmente, apenas inicia nos primeiros passos nesta temática e não possui histórico ou experiência nestas ações, faz-se necessário buscar, fora da instituição, consultorias especializadas que possam contribuir com sua experiência na implantação das políticas de promoção da igualdade racial, nos moldes do que se busca implementar na UTFPR.

É preciso a construção de pesquisas interdisciplinares não apenas em uma perspectiva teórica e metodológica enquanto elemento passível do campo das Ciências Sociais, como também na perspectiva de construção de políticas que honrem o conhecimento histórico, sociológico e tecnológico desta instituição. Casos recentes de racismo no país, em diversas esferas, desde um estádio de futebol na qual o jogador é chamado por milhares de torcedores de "macaco" a um contexto de perseguição nas salas de aula aos alunos cotistas, devido a cor de pele ou ao suposto cabelo "ruim", constituem provas de o quanto ainda é preciso trabalhar e lutar para construir um mundo justo e igualitário!

Superar o racismo, combater o racismo institucional, contribuir para o empoderamento dos alunos cotistas, instrumentalizando-os para defenderem-se desta sociedade injusta, constitui sim, também missão de uma universidade tecnológica. Uma missão para muito além da formação técnica e tecnológica. O NEABI (Núcleo de Estudos Afro-Brasileiros e Indígenas) da UTFPR pode e deve contribuir grandemente para que todo este processo ocorra da forma mais eficiente possível. Recomenda-se, assim seu fortalecimento, instituicionalização e ampliação. 


\section{REFERÊNCIAS}

AMORIM, Mário Lopes (2010). "A Escola Ténica de Curitiba/Escola Técnica Federal do Paraná". In: Tecnologia e Humanismo, Ano 24, N. 39, julho-dezembro, p. 169-212.

BASTOS, João Augusto de S. L. (org) (1998). Tecnologia e interação. Publicação do Programa de Pós-Graduação em tecnologia PPGTE/CEFET-PR. Curitiba: CEFET-PR.

BENTO, Maria Aparecida Silva. (2003). "Branqueamento e branquitude no Brasil". In: Psicologia social do racismo: estudos sobre branquitude e branqueamento no Brasil. 2. ed. CARONE, Iray; BENTO, Maria Aparecida (Organizadoras) Petrópolis, RJ: Vozes, p. (25-58).

BRASIL (2012). LEI № 12.711, DE 29 DE AGOSTO DE 2012. Dispõe sobre o ingresso nas universidades federais e nas instituições federais de ensino técnico de nível médio e dá outras providências

CARVALHO, Marília G. (1997). Tecnologia, desenvolvimento social e educação tecnológica. In: Revista Educação \& Tecnologia, Curitiba, Ano 1, n.1, p:70-87, jul.

FIGUEIREDO, Vilma (1989). Produção social da tecnologia. São Paulo: EPU.

GURSKI JUNIOR, Lauro (2010). "Escola de Aprendizes Artífices do Paraná (1935-1945)". In: Tecnologia e Humanismo, Ano 24, N. 39, julho-dezembro, p. 113-168.

KUENZER, Acácia Zeneida (1992). Ensino de 2o grau: o trabalho como princípio educativo. 2a ed. SP: Cortez.

MEDEIROS, Jussara Marques de (2015). A política de cotas na Universidade Tecnológica Federal do Paraná. Curitiba: Mestrado PPGTE (Tecnologia e Trabalho.

SANTOS, Milton (1998). Entrevista na Revista Caros Amigos, no 17. São Paulo, agosto de 1998. Disponível em http://www.carosamigos.com.br/index.php/grandes-entrevistas/6047entrevista-explosiva-com-milton-santos. Acesso em 13.novembro.2016

TEIXEIRA, Selma Suely (2010). "UTFPR 1970-2000: de Escola Técnica à Universidade Tecnológica Federal do Paraná". In: Tecnologia e Humanismo, Ano 24, N. 39, julho-dezembro, p. 213-294.

QUELUZ, Gilson Leandro (2010). "Escola de Aprendizes Artífices do Paraná (1909-1930)". In: Tecnologia e Humanismo, Ano 24, N. 39, julho-dezembro, p. 39-112. 